\title{
ANÁlISE DA BIODEGRADAÇÃo dOS COMPONENTES dO ÓlEO CÍTRICO POR CG/EM E ANÁLISE DA POPULAÇÃO MICROBIANA DE UM REATOR DE LODO ATIVADO NO TRATAMENTO DE ÁGUA RESIDUÁRIA DE UMA INDÚSTRIA CÍTRICA
}

\section{ANALYSIS OF BIODEGRADATION OF CITRIC OIL COMPOUNDS BY GC/MSD AND ANALYSIS OF THE MICROBIAL POPULATION OF AN ACTIVATED SLUDGE REACTOR IN THE TREATMENT OF A CITRIC WASTEWATER}

\begin{abstract}
ALEXANDRE NUNES PONEZI
Biólogo. Mestrado em Engenharia de Alimentos FEA/UNICAMP. Doutorado em Engenharia Civil. Departamento de Saneamento e Ambiente FEC/UNICAMP. Pesquisador do CPQBA/UNICAMP - Divisão de Microbiologia. Coordenador da Divisão de Microbiologia CPQBA/UNICAMP
\end{abstract}

\section{Marta CRISTINA TEIXEIRA DUARTE}

Bióloga. Mestrado em Biologia Vegetal - Sub-área Bioquímica de Microrganismos IB/Unesp/Rio Claro. Doutorado na referida área, IB/Unesp/Rio Claro. Pesquisadora TPCT CPQBA/UNICAMP - Divisão Microbiologia

\section{BRUNO CORAUCCI FILHO}

Professor Associado - Universidade Estadual de Campinas. Faculdade de Engenharia Civil,

Departamento de Saneamento e Ambiente

\section{ROBERTO FEIJO DE FIGUEIREDO}

$\mathrm{PhD}$, University of California. Professor Associado - Universidade Estadual de Campinas. Faculdade de Engenharia Civil. Departamento de Saneamento e Ambiente

Recebido: 15/04/04 Aceito: 18/08/05

\section{RESUMO}

Água residuária da indústria cítrica foi utilizada como objeto de estudo de biodegradação através de um sistema de lodo ativado por batelada. As análises realizadas por CG/EM mostraram que os compostos provenientes do óleo de laranja como o limoneno, foram resistentes a biodegradação. A avaliação microbiológica realizada no decorrer do período mostrou que o número e tipo de colônias bacterianas variaram de acordo com o tempo, e pode ser observada uma sucessão de microrganismos durante a biodegradação do efluente cítrico. $\mathrm{O}$ microrganismo identificado como LAB-9 (Pseudomonas struzieri) e LAB-7 (não identificado) prevaleceram durante todo o processo, sugerindo que estes são organismos importantes para remoçáo da matéria orgânica no processo ou são melhores adaptados ao tipo de água residuária. O sistema de lodo ativado foi eficiente na redução de $\mathrm{DBO}$ e DQO, alcançando valores de 79 e $78 \%$ respectivamente, num período de 15 h de reação, com uma relação F/M 4:2.

PALAVRAS-CHAVES: Lodos ativados, CG/EM população microbiana, efluente cítrico.

\begin{abstract}
Wastewater from citric industry was used to biodegradation study through an activated sludge system. The analyses accomplished by CG/MSD showed that compounds of the orange oil as the limoneno, was resistant to biodegradation. The microbiological evaluation developed during the biodegradation period showed that the number and type of bacteria present in the system varied according to the time, and a succession of microorganisms can be observed. The microrganism identified as LAB-9 (Pseudomonas struzieri) and $L A B-7$ (not identified) prevailed during whole the process, suggesting that they were the main responsible for the removal of the organic matter or the better adapted to the type of wastewater. The system of activated sludge was efficient in the reduction of $D B O$ and $D Q O$, reaching values of 79 and $78 \%$, respectively, in a period of $15 \mathrm{~h}$, with a relationship F/M 4:2.
\end{abstract}

KEYWORDS: Activated sludge, GC/MSD, microbial population, citric wastewater. 


\section{INTRODUÇÃO}

O sistema de lodo ativado é amplamente utilizado para o tratamento de despejos domésticos e industriais, em situações onde são necessários uma elevada qualidade do efluente final e reduzidos requisitos de área (Sperling, 1997). Este sistema de tratamento está baseado na capacidade microbiana em catabolisar diferentes compostos orgânicos naturais e/ou sintéticos, e inorgânicos, utilizando estes substratos como fontes nutricionais e energéticas, possibilitando sua utilização como solução aos problemas gerados pelo lançamento de rejeitos ao meio ambiente. Esta resposta ao metabolismo de certos microrganismos, sem dúvida, tem conferido algumas vantagens adicionais à biotecnologia ambiental, tais como a exploração de novos nichos ecológicos (Vazoller, 1997). A análise da literatura mostra que várias pesquisas têm sido realizadas com o intuito de se conhecer a microbiota existente em plantas de tratamento de lodos ativados, objetivando a melhoria dos processos existentes principalmente na biodegradação de compostos de interesse sanitário.

O limoneno, principal constituinte dos óleos essenciais da laranja $(0,92 \%)$, é um líquido oleoso incolor, obtido da destilação do licor cítrico com uma produção de 38,5 ton/ano safra 2003/2004. Este produto é obtido da prensagem do resíduo úmido da laranja (casca, bagaço, semente) após a extração do suco (ABECITRUS, 2004; Thomas \& Bessiére, 1989). O limoneno merece uma atenção especial devido a sua toxicidade aos microrganismos presentes nos sistemas de tratamento como também a alguns insetos comumente encontrados em efluentes da indústria cítrica (Bwoen, 1975; Uribe \& Pena, 1990).

Técnicas cromatográficas como CG/EM têm sido empregadas em trabalhos de pesquisa onde existe o interesse em acompanhar a biodegradação de compostos alvos pelos microrganismos presentes no sistema de lodos ativados. Os resultados mostram que vários compostos químicos, orgânicos e inorgânicos são passíveis de serem metabolizados durante o tratamento, porém alguns destes apresentam resistência à degradação, sugerindo a aplicação de tratamento posterior ao tratamento biológico secundário.

Estudos mais detalhados dos microrganismos envolvidos no processo de biodegradação da matéria orgânica, através de tratamento biológico aeróbio de resíduos se fazem necessários para um melhor entendimento do processo de biodegradação do efluente, durante os ciclos desse tipo de sistema. Assim, os objetivos deste trabalho foram: estudar a biodegradação do óleo cítrico em sistema de lodo ativado usando-se a técnica de cromatografia gasosa acoplada a espectrometria de massa $(\mathrm{cg} / \mathrm{em})$ e identificar a população microbiana nos reatores $\mathrm{du}$ rante o período de tratamento.

\section{MATERIAL E MÉTODOS}

\section{Água residuária da indústria cítrica}

Água residuária oriunda da indústria cítrica foi utilizada como matéria-prima para o desenvolvimento do trabalho. A coleta do efluente industrial foi realizada separadamente das instalaçóes sanitárias, em vertedouro situado logo após o decantador primário, não sendo realizada a correção de $\mathrm{pH}$ e de nutriente nesta fase.

\section{Características do efluente cítrico}

Os parâmetros físicos, químicos e biológicos do efluente cítrico foram analisados seguindo a metodologia proposta pelo "Standard Methods for the Examination of Water and Wastewater" 14 ed, 1976, quanto a: Demanda bioquímica de oxigênio (DBO), método 5-2 e 5-4 (1989); Demanda química de oxigênio (DQO), método 5-10 (1989); $\mathrm{pH}$; Temperatura; Série de sólidos, método 2-71 (1989); Oxigênio dissolvido (OD); e Nitrogênio método 14 e Fósforo método 13 seguindo a metodologia proposta por Macedo, (2001).

\section{Descrição e montagem da unidade piloto}

Os dois reatores utilizados neste trabalho foram fabricados em acrílico com o fundo em forma de tronco de pirâmide invertido, o que auxilia na sedimentação, e na operação de descarte de lodo e distribuição de oxigênio atmosférico. Cada reator possui capacidade nominal de $12,0 \mathrm{~L}$ sendo 10,0 L de efluente e 2,0 L de lodo que permanece no fundo do reator para partida em cada ciclo. Para se fazer a drenagem do efluente tratado os reatores possuíam um orifício na parte lateral acima do nível de lodo. A aplicação de ar atmosférico $\left(2,0 \mathrm{~L} / \mathrm{min}^{-1}\right)$ e o descarte de lodo foi realizada por orifícios localizados no fundo do reator.

O efluente industrial a ser tratado foi bombeado através de bomba peristáltica para a parte superior dos reatores após correção de $\mathrm{pH}$ e nutrientes.

\section{Operação dos reatores}

A operação dos reatores foi conduzida segundo Dornellas (1990), com uma concentração de SSV de $2.500 \mathrm{mg} / \mathrm{L}$ em cada ciclo de reação de 14 horas, sendo 2 horas para o período de enchimento, 10 horas de reação, 30 minutos de sedimentação, 30 minutos de drenagem e 1 hora de repouso. Os reatores foram operados por 108 dias.

A correção de nutrientes foi realizada segundo Metcalf \& Eddy (1991), com uma relação 100:5:2 (DQO:N:P), utilizando uréia e ácido fosfórico como fontes de nutrientes. $\mathrm{O}$ pH foi ajustado para pH 7,0 após a correção de nutrientes.

\section{Isolamento dos microrganismos presentes nos reatores}

O isolamento dos microrganismos presentes nos reatores foi realizado através da técnica de plaqueamento por diluição em tubos múltiplos, onde $1 \mathrm{~mL}$ da mistura em reação (lodo/efluente) foi transferido para meio PCA (Plate Count Agar - Difco), seguido de incubação a $28^{\circ} \mathrm{C} \pm 1^{\circ} \mathrm{C}$ por um período de $24 \mathrm{a} 48 \mathrm{~h}$. A contagem das colônias foi realizada por observação direta das placas, sem tratamento estatístico. As coletas de amostras foram realizadas após o período de enchimento, a intervalos de 3 horas até o final do período de reação. O isolamento dos microrganismos presentes nos reatores foi realizado após serem determinadas as melhores condiçôes para o tratamento do efluente cítrico totalizando 6 ciclos de reaçãa.

\section{Identificação e caracterização dos microrganismos isolados}

A caracterização morfológica das colônias quanto à forma, tamanho, cor, textura entre outras foi feita através de observação visual em microscópio estereoscópico modelo Estéreo Zoom (Cambridge Instruments). Todas as colônias crescidas nas placas foram separadas por suas características morfológicas, contadas e isoladas para posterior identificaçôes. A identificação dos principais mi- 
crorganismos encontrados e isolados do sistema LAB foi feita junto à Fundação Tropical de Pesquisas e Tecnologia "André Tosello", no nível de espécie através de métodos bioquímicos.

\section{Pré-tratamento e análise das amostras por CG/EM durante $o$ período de tratamento}

O pré-tratamento consistiu em coletar amostras de $500 \mathrm{~mL}$ e submetê-las à filtração sob vácuo, com diferentes tipos de filtros de granulometria variada (fibra de vidro AP 20, AW06, 045 $\mu \mathrm{m}$ e $022 \mu \mathrm{m}$ Millipore) obtendo-se assim um material limpo e transparente de cor amarela, sem perda de suas características iniciais. Foram coletadas três amostras para cada período de reação durante quatro ciclos completos de tratamento.

A metodologia utilizada para a extração das substâncias do efluente cítrico foi a de partição, onde $500 \mathrm{~mL}$ da amostra do efluente foram separados e o $\mathrm{pH}$ corrigido para valores menores ou iguais a 2 com ácido sulfúrico concentrado, sob agitação magnética. Frações de $200 \mathrm{~mL}$ deste material foram adicionados de $70 \mathrm{~mL}$ de clorofórmio e agitadas em funil de separação. Este procedimento foi repetido por 3 vezes, e as respectivas fraçôes combinadas. Para a retirada de água proveniente do processo, o material foi submetido à secagem com sulfato de sódio anidro. A amostra foi submetida a rota-evaporação para retirada do solvente utilizado na extração, quase até a secura, em banho à $40^{\circ} \mathrm{C}$. O material foi então ressuspendido em acetato de etila para um volume de $1,0 \mathrm{~mL}$.

A análise dos compostos químicos gerados durante o tratamento do efluente industrial foi realizada em cromatógrafo gasoso com detetor de ionização de chama (FID) e detetor seletivo de massa (MSD), modelo HP-5970, equipados com colunas cromatográficas capilares (coluna AP-1 no caso do FID; e coluna AP-5 no caso do MSD). As condições empregadas nas análises nos cromatógrafos foram as seguintes: Coluna-AP-1; $\mathrm{AP}-5,30$ metros; Injetor $-250^{\circ} \mathrm{C}$; Detetor - $280^{\circ} \mathrm{C}$; Condições - início $70^{\circ} \mathrm{C}$; rampa $3^{\circ} \mathrm{C} / \mathrm{min}$; término $300^{\circ} \mathrm{C}$; $5 \mathrm{~min} / 300^{\circ} \mathrm{C}$; Amostra - $1 \mu \mathrm{L}$. O efluente líquido industrial também foi monitorado para averiguação de suas condições antes de serem submetidos ao tratamento.

Neste trabalho, os principais componentes químicos identificados através de espectrofotometria de massa nas amostras do despejo industrial, e as geradas durante a biodegradação pelos microrganismos durante o período de tratamento do efluente foram comparados com os espectros constantes da biblioteca do próprio equipamento. Uma amostra de limoneno purificado comercial, cedido pela indústria cítrica foi utilizada como indicador de reciprocidade com os espectros da biblioteca do equipamento, sendo esta aprovada para realização dos experimentos com $97,8 \%$ pureza.

\section{RESULTADOS E DISCUSSÃO}

\section{Características da água residuária da indústria cítrica}

As principais características físicoquímicas da água residuária estudada encontram-se descritas na Tabela 1 . Os resultados da análise cromatográfica das amostras do efluente cítrico podem ser observados na Figura 1 e Tabela 2.

Tabela I - Valores médios dos parâmetros obtidos na caracterização do efluente cítrico bruto

\begin{tabular}{cc}
\hline Parâmetros observados & Valores médios \\
\hline Demanda química de oxigênio - DQO $\left(\mathrm{mgO}_{2} / \mathrm{L}\right)$ & $3989 \pm 326^{(20)}$ \\
Demanda bioquímica de oxigênio - $\mathrm{DBO}\left(\mathrm{mgO}_{2} / \mathrm{L}\right)$ & $1276 \pm 263^{(20)}$ \\
Sólidos suspensos totais $(\mathrm{mg} / \mathrm{L})$ & $317 \pm 187^{(20)}$ \\
Sólidos suspensos fixos $(\mathrm{mg} / \mathrm{L})$ & $263 \pm 171^{(20)}$ \\
Sólidos suspensos voláteis $(\mathrm{mg} / \mathrm{L})$ & $352 \pm 178^{(20)}$ \\
pH & $8,5-4,25^{(20)}$ \\
Sólidos sedimentáveis $(\mathrm{ml} / \mathrm{L})$ & $23 \pm 20^{(20)}$ \\
Fósforo $(\mathrm{mg} / \mathrm{L})$ & $2,8-0,8^{(10)}$ \\
Nitrogênio Total $(\mathrm{mg} / \mathrm{L})$ & $12-8^{(10)}$ \\
\hline
\end{tabular}

$\left(n^{\circ}\right)=$ número de dias amostrados.

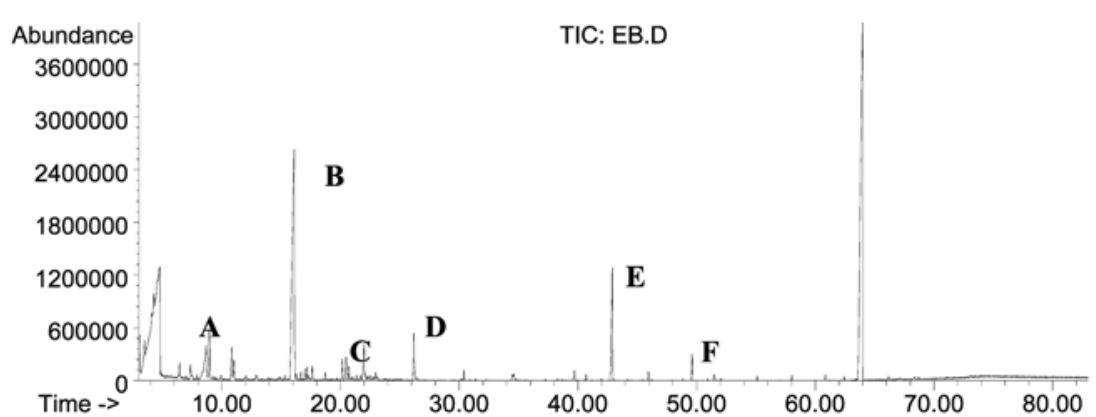

Figura I - Cromatograma do efluente industrial bruto por CG/EM. As letras representam os principais componentes químicos do efluente bruto industrial relacionado na Tabela 2

Tabela 2 - Principais componentes químicos do efluente bruto industrial (CG/EM)

\begin{tabular}{ccc}
\hline Id & Tempo de retenção $(\mathrm{min})$ & Identificação \\
\hline A & 7,35 & Fenol \\
B & 16,10 & $\alpha$ - Terpineol \\
C & 22,00 & Limoneno \\
D & 26,18 & Tetradecano \\
E & 42,90 & Ácido benzóico \\
F & 49,50 & Ftalato \\
\hline
\end{tabular}




\section{Adaptação do lodo}

A adaptação do lodo (esgoto doméstico) ao efluente cítrico foi concluída em 26 dias com uma concentração inicial de $2.500 \mathrm{mg} / \mathrm{L} \mathrm{SSV}$ para a partida dos reatores. Esta fase inicial de adaptação do esgoto doméstico frente a um efluente industrial é uma etapa crucial para o bom desempenho dos reatores, e seleciona os microrganismos melhores adaptados às condições nutricionais do meio. Além disso, durante esta fase pode ser observado a formação de flocos e acompanhar a micro fauna mais freqüente quanto ao número e tipo de protozoários. O tempo de duração desta fase varia de acordo com a complexidade do meio efluente. Outros pesquisadores concluíram esta fase de adaptação em 14 dias para o mesmo tipo de efluente (Povinelli et al, 1988; Dornellas, 1996). Na Tabela 3 são apresentados os resultados dos parâmetros analisados durante o período de adaptação.

\section{Eficiência dos reatores de lodo ativados durante $o$ período de tratamento}

Os reatores A e B operados segundo as condiçôes apresentadas no item operação de reatores apresentaram uma eficiência na redução de $\mathrm{DBO}$ de $79 \% \pm 3,5$ e de $\mathrm{DQO}$ de $78 \% \pm 1,4$. Os reatores de lodos ativados mostraram uma grande estabilidade em sua eficiência, pois os valores apresentados acima não sofreram grandes modificações após 12 dias de amostragem. A remoção de sólidos foi de $98 \%$ para ambos os reatores. A concentração máxima de SSV obtida durante o período do experimento foi de $4.500 \mathrm{mg} / \mathrm{L}$. O pH não apresentou alteração durante todo o período de experimento mantendo-se em pH 7,2 monitorado através de sonda posicionada no reator.

\section{Contagem, isolamento e identificação dos microrganismos}

A contagem dos microrganismos presentes no meio de reação (lodo/efluente), realizada através de plaqueamento, estão apresentadas na Figura 2 para os reatores A e B. As colônias presentes foram aquelas capazes de crescer nas condições experimentais e metodológicas escolhidas para a realização deste trabalho.

Embora os resultados obtidos sejam limitados quanto aos tipos de microrga- nismos presentes nos reatores, foi possível observar uma variação do número de colônias (Figura 2) e tipos de bactérias (Tabela 4) presentes em cada fase do processo de tratamento do despejo cítrico.

Através da contagem das colônias (UFC) realizada durante o período de reação de 15 horas foi possível observar que o crescimento bacteriano se deu durante as primeiras 6 horas de reação, seguida de uma fase estacionária entre 6 e 8 horas. Após 8 horas de operação foi verificado que o número de colônias começou a diminuir lentamente, indicando a fase de declínio do lodo. A curva de crescimento/decaimento dos microrganismos durante o período de reação é ilustrada na Figura 2, e segue o esquema proposto por Metcalf \& Eddy (1990) para curva de crescimento bacteriano para este tipo de tratamento.

$\mathrm{O}$ isolamento e identificação dos microrganismos dos reatores durante o período de reação mostraram a presença de duas espécies de leveduras e nove espécies de bactérias, às quais foram atribuídos códigos para identificação (Tabela 4).

A análise dos microrganismos presente nos reatores durante o período de operação mostrou que as bactérias identificadas como Pseudomonas stutzeri (LAB-9) e LAB-7 (não identificada) estavam presentes durante todo o processo, principalmente nos períodos entre 6 a 9 horas, no qual estas foram predominantes, indicando atividade relevante na biodegradação do efluente cítrico.

Os microrganismos identificados como Serratia marcescens (LAB-1), Geotrichum klebahnii (LAB-2) e LAB-3 (não identificada) estavam presentes apenas na fase inicial do período de reação (3 horas). Somente a bactéria LAB-3 permaneceu após o período de 6 horas de reação. As demais bactérias presentes nos reatores ocorreram em quantidades reduzidas durante a fase de reação, o que indi-

Tabela 3 - Concentração de sólidos suspensos no lodo durante o período de adaptação

\begin{tabular}{ccccccc}
\hline Período $\left(\mathrm{d}^{-1}\right)$ & \multicolumn{3}{c}{ Reator A } & \multicolumn{3}{c}{ Reator B } \\
& SST & $\begin{array}{c}\text { SSF } \\
(\mathrm{mg} / \mathrm{L})\end{array}$ & SSV & SST & $\begin{array}{c}\text { SSF } \\
(\mathrm{mg} / \mathrm{L})\end{array}$ & SSV \\
\hline 7 & 356 & 292 & 64 & 356 & 28 & 328 \\
11 & 340 & 44 & 296 & 228 & 100 & 128 \\
13 & 520 & 50 & 470 & 405 & 85 & 320 \\
15 & 370 & 50 & 320 & 1273 & 700 & 573 \\
17 & 673 & 100 & 573 & 640 & 113 & 527 \\
24 & 1958 & 443 & 1515 & 3200 & 550 & 2650 \\
26 & 2580 & 320 & 2260 & 3620 & 486 & 3134 \\
\hline
\end{tabular}

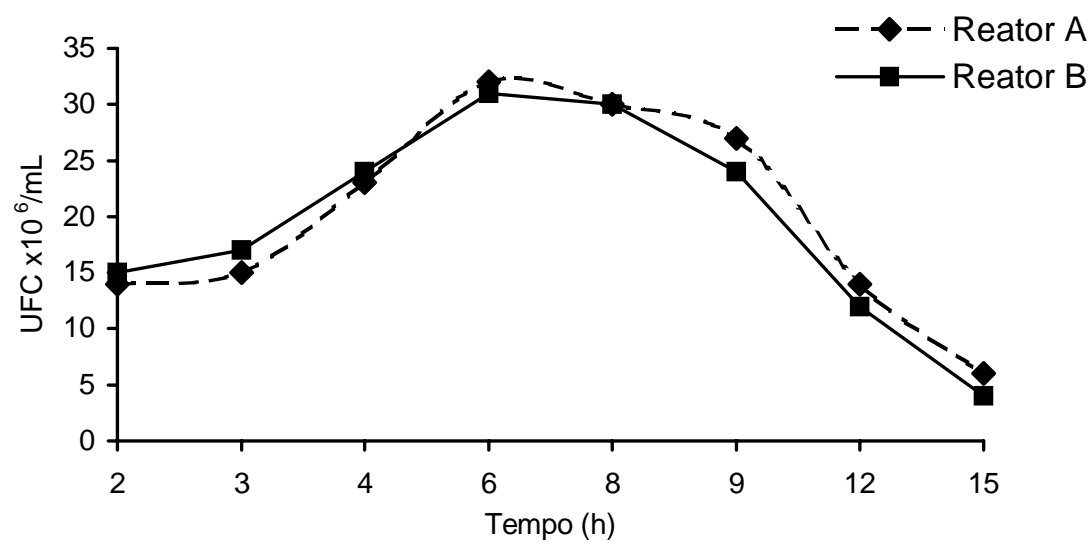

Figura 2 - Resultados do crescimento/decaimento dos microrganismos durante o período de reação 
Tabela 4 - Identificação dos microrganismos encontrados nos reatores durante o processo de tratamento da água residuária da indústria cítrica

\begin{tabular}{cccc}
\hline Código & Identificação & Código & Identificação \\
\hline LAB-1 & Serratia marcescens & LAB-2 & Geotrichum klebahnii \\
Bactéria & & Levedura & \\
LAB-3 & NI & LAB-4 & Pseudomonas stutzeri \\
Bacteria & & Bactéria & \\
LAB-5 & NI & LAB-6 & NI \\
Bacteria & & Bactéria & \\
LAB-7 & NI & LAB-8 & Achromobacter xylosoxidans \\
Bacteria & & Bactéria & subsp. denitrificans \\
LAB-8b & Candida tropicalis & LAB-9 & Pseudomonas stutzeri \\
Levedura & & Bactéria & \\
LAB-10 & Clavibacter michiganensis & & \\
Bactéria & & & \\
\hline
\end{tabular}

NI = Não identificada.

ca que a participação destes organismos no tratamento do efluente cítrico é específica para subprodutos gerados durante o processo de biodegradação ou produtos específicos do próprio efluente industrial. As três espécies de microrganismos citadas acima são organismos comumente encontrados em sistemas de tratamento por lodos ativados.

No caso da linhagem identificada como Achromobacter xylosoxidans subsp. Denitrificans trata-se de um organismo gram negativo, não fermentador, identificado inicialmente por Rüger and Tan (1983), e posteriormente reclassificada por Coenye et al (2003) como Achromobacter xylosoxidans subsp. Denitrificans comb nov. Este microrganismo é comumente encontrado em solo, água e ambientes hospitalares. Kersters \& De Ley (1984) relataram em seus estudos que esta espécie é capaz de causar uma grande variedade de infecçôes oportunistas tanto para o homem como para organismos aquáticos oligotróficos. As análises qualitativas do lodo realizadas por exames microscópios durante todo o período experimental mostraram que este apresentava uma variação na relação entre os tamanhos de filamentos de $10^{3}$ a $10^{5}(\mathrm{bac} / \mathrm{mL})$ e flocos variando de $80 \mathrm{a} 400 \mu \mathrm{m}$ de diâmetro. Quanto à relação de microrganismos indicadores de boas condiçōes de depuração foi possível observar a presença de uma grande quantidade de protozoários com predominância de ciliados (pedunculados e livres). Os resultados obtidos sobre a microfauna podem se comparados com os resultados obtidos por Vazoller et al (1986) e Metcalf \& Eddy (1991).

\section{Análise cromatográfica da água residuária da indústria cítrica para identificação dos compostos químicos presentes}

Devido ao grande número de substâncias químicas presentes no efluente, foram selecionados apenas os compostos pertencentes ao óleo cítrico, para acompanhamento de sua biodegradação durante o período de tratamento. Os resultados indicam redução dos principais compostos químicos originais a compostos secundários de menor massa molecular pelos microrganismos durante o período de reação, evidenciando a adaptabilidade microbiológica na degradação química do resíduo.

Segundo Kimball (1991) o óleo cítrico é composto basicamente de $90 \%$ de limoneno e $10 \%$ de outros terpenos. Shaw (1977) mencionou que os compostos orgânicos voláteis, principalmente o óleo, são uma barreira natural de controle microbiológico e também de insetos para o fruto, sendo a fração $\delta$-limoneno tóxico para o ser humano, podendo causar irritação na pele e olhos. Este mesmo autor descreveu que a contaminação do efluente industrial com altos níveis de d-limoneno pode causar distúrbios no sistema de tratamento de efluentes, justamente pela toxicidade que representa para os microrganismos presentes no sistema.

A degradação do limoneno tem início pela hidroxilação, na posição 1 e 2 do anel aromático, à $\alpha$-terpineol (Demyttenaere et al, 2001; De Oliveira \& Strapasson, 2000; De Oliveira \& Durrant, 2001;
Júnior \& Pastore, 2001). Através dos resultados das análises realizadas por CG/EM foi possível confirmar que o principal componente do óleo cítrico, o d-limoneno (G) foi parcialmente metabolizado originando como produto metabólico secundário o a-terpineol (B) em quantidade superior a encontrada no efluente bruto. Outras substâncias representativas como o cis-carveol (C), $\beta$-citronelol (D), trans-geraniol (E) e $\beta$-santalol (F) foram reduzidas após 3 horas de reação.

Compostos com anéis aromáticos como o fenol (A), tetradecano (H) e ácido benzóico (I), não foram reduzidos (metabolizados) durante o período de tratamento, indicando que os microrganismos presentes nos reatores não possuem sistema enzimático capaz de biodegradar estas classes de compostos químicos. Os resultados das análises podem ser observados na Tabela 5 e Figuras 3 a 6 .

\section{CONCLUSÕES}

As análises dos componentes do óleo cítrico por CG/EM mostraram que uma parte do limoneno presente no efluente foi transformada em um terpeno secundário ( $\alpha$-terpineol), indicando a presença de microrganismos capazes de utilizar o óleo como fonte de carbono. No entanto, não foi observada a completa utilização deste composto durante o período de reação, o que pode levar a um acúmulo no efluente, causando distúrbios nos reatores devido a sua toxicidade aos microrganismos responsáveis pela biodegradação do mesmo. O acompanhamento da microbiota dos sistemas de lodos ativados durante o período de reação permitiu identificar diferentes tipos de microrganismos em função do tempo. $\mathrm{O}$ isolamento e a identificação de espécies presentes nos reatores indicaram possíveis responsáveis pela biodegradação do efluente cítrico estudado. O conhecimento da microbiota dos reatores de lodos ativados é de grande valia, pois podem ser identificados tipos ou grupos de bactérias responsáveis pela degradação de compostos de interesse sanitário. A combinação destas duas metodologias aplicadas as atuais plantas de tratamento aeróbias, anaeróbias ou tratamento combinado pode ser de grande utilidade para o entendimento do processo metabólico do efluente a ser tratado. 
Tabela 5 - Análise dos principais compostos químicos do óleo cítrico por

CG/EM durante o período de tratamento. As letras (Id) indicam os compostos químicos apresentados nas Figuras 3 a 6

\begin{tabular}{ccccccc}
\hline Id & $\begin{array}{c}\text { Tempo } \\
\text { retenção }(\mathrm{min})\end{array}$ & Identificação & EB & $\begin{array}{c}3 \\
\text { horas }\end{array}$ & $\begin{array}{c}9 \\
\text { horas }\end{array}$ & $\begin{array}{c}15 \\
\text { horas }\end{array}$ \\
\hline A & 7,36 & Fenol & $\mathrm{x}$ & $\mathrm{x}$ & $\mathrm{x}$ & $\mathrm{x}$ \\
$\mathrm{B}$ & 16,17 & o-terpineol & $\mathrm{x}$ & $\mathrm{x}$ & $\mathrm{x}$ & $\mathrm{x}$ \\
$\mathrm{C}$ & 17,02 & Cis-carvenol & $\mathrm{x}$ & & & \\
$\mathrm{D}$ & 17,63 & $\beta$-citronelol & $\mathrm{x}$ & & & \\
$\mathrm{E}$ & 18,72 & Trans-geraniol & $\mathrm{x}$ & & & \\
$\mathrm{F}$ & 20,15 & $\beta$-santalol & $\mathrm{x}$ & $\mathrm{x}$ & & \\
$\mathrm{G}$ & 22,01 & Limoneno & $\mathrm{x}$ & $\mathrm{x}$ & $\mathrm{x}$ & $\mathrm{x}$ \\
$\mathrm{H}$ & 26,20 & Tetradecano & $\mathrm{x}$ & $\mathrm{x}$ & $\mathrm{x}$ & $\mathrm{x}$ \\
$\mathrm{I}$ & 42,94 & Ácido benzóico & $\mathrm{x}$ & $\mathrm{x}$ & $\mathrm{x}$ & $\mathrm{x}$ \\
\hline
\end{tabular}

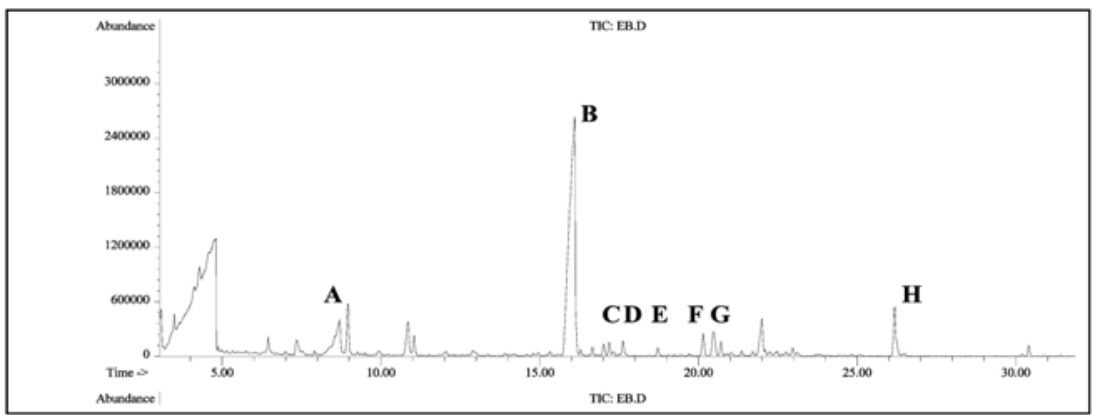

Figura 3 - Cromatograma do efluente bruto da indústria cítrica. As letras indicam os principais compostos químicos listados na Tabela 5

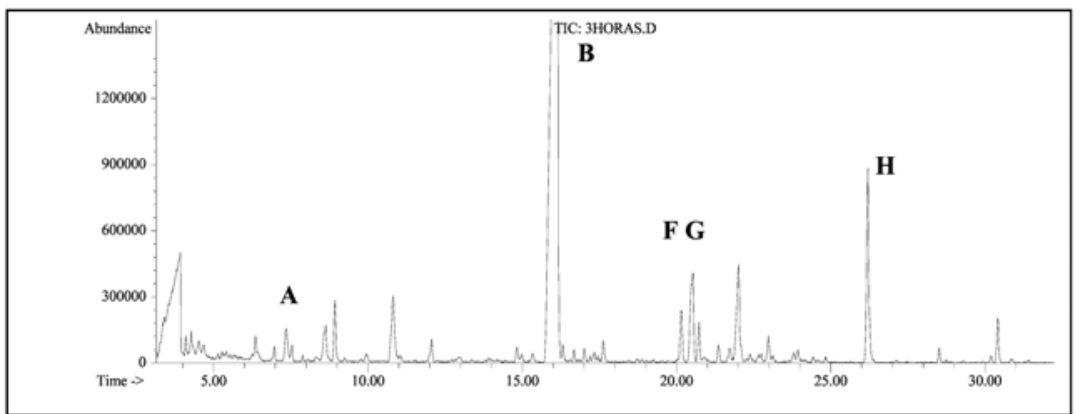

Figura 4 - Cromatograma do efluente bruto da indústria cítrica após 3 horas de reação. As letras indicam os principais compostos químicos listados na Tabela 5

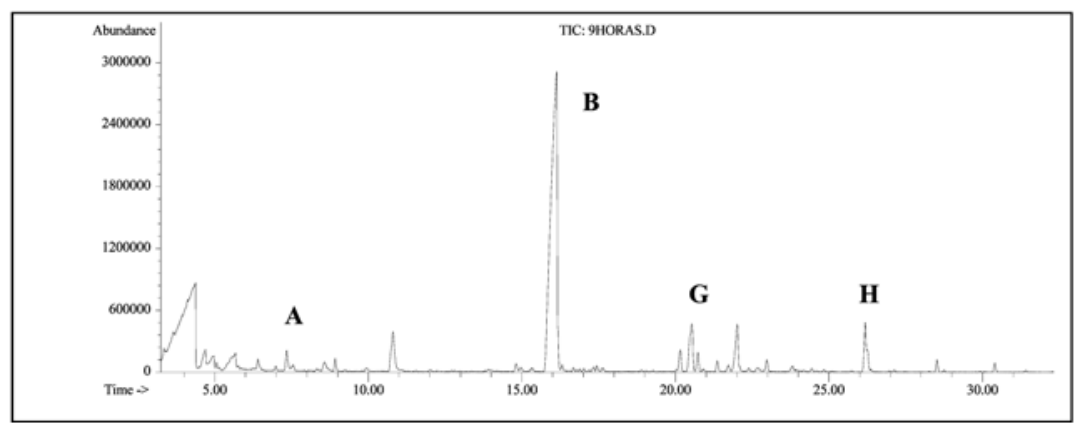

Figura 5 - Cromatograma do efluente bruto da indústria cítrica após 9 horas de reação. As letras indicam os principais compostos químicos listados na Tabela 5 


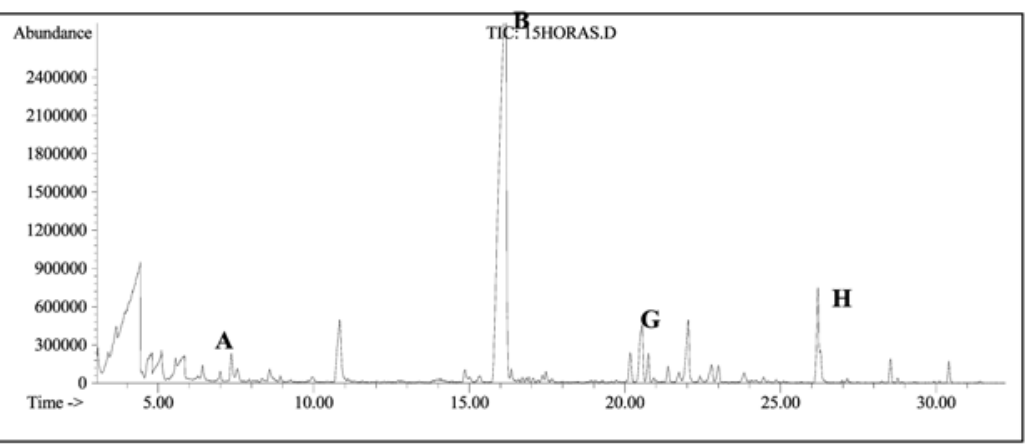

Figura 6 - Cromatograma do efluente bruto da indústria cítrica após I5 horas de reação. As letras indicam os principais compostos químicos listados na Tabela 5

\section{AGRADECIMENTOS}

A FAPESP pelo suporte financeiro para a realização desta pesquisa.

\section{REFERÊNCIAS}

ABECITRUS, 2004 - www.abecitrus.com.br BWOEN, E.R. Potential by products from microbial transformation of d-limonene. Florida State horticultural society, p 304, 1975.

COENYE, T. et al. Kerstersia gyiorum gen. nov., sp. nov., a novel Alcaligenes faecalis-like organism isolated from human clinical samples, and reclassification of Alcaligenes denitrificans Ruger and Tan 1983 as Achromobacter denitrificans comb. nov. Int. J. Syst. Evol. Microbiol. (53) 1825-1831, 2003.

DE OLIVEIRA, A L. \& DURRANT, L.R. Isolamento e seleção de microrganismos capazes de degradas o d-limoneno. In: IX CONGRESSO INTERNO DE INICIAÇÃO CIENTÍFICA DA UNICAMP, 2001.

DE OLIVEIRA, B. H. \& STRAPASSON, R.A Biotransformation of monoterpene, limonene, by Fusarium verticuloides. Brasilian archives of bioloy and technology. V. 43, $\mathrm{n}^{\circ} 1, \mathrm{p}, 11-14$, 2000 .

DEMYTTENAERE, J.C.R.; VAN BELLEGHEM, K.; DE KIMPE, N. Biotransformation of ${ }^{\circledR} \alpha$ and $\beta$ limonene by fungi and the use of solid phase microextraction for screening. Phytochemistry, v. 57, n'2, p. 199-208, 2001. quido da indústria cítrica pelo processo de lodo ativado por batelada (Lab) com aplicação de oxigênio puro. Dissertação de Mestrado, Faculdade de Engenharia Civil, Universidade Estadual de Campinas, 1990

JÚNIOR, M.R.M \& PASTORE, G.M. Biotransformação de d-limoneno para obtenção de compostos de aroma. In: IX CONGRESSO INTERNO DE INICIAÇĀO CIENTÍFICA DA UNICAMP, 2001.

KERSTERS, K. \& DE LEY, J. Genus Alcaligenes Castellani and Chalmers 1919, 936 $6^{\mathrm{AL}}$. In: Bergey's Manual of Systematic Bacteriology, vol. 1, pp. 361-373, Edited by N. R. Krieg \& J. G. Holt. Baltimore: Williams \& Wilkins. 1984

KIMBALL, D. A. Citrus processing: quality control and technology. Chapman \& Hall ed., New York, 1991.

MACEDO, J.A.B. Métodos Laboratoriais de análises físico-quimicas e microbiológicas. Juiz de Fora Minas Gerais, 2001

METCALF \& EDDY. Wastewater Engineering: treatment, disposal, reuse. 3.Ed. New York: Mcgraw Hill, P.83, 90-93, 364-369, 374377 , 384-389, 531-546, 1265-1266, 1275 1277, 1991

PONEZI, A. N. Tratamento de efluente líquido da indústria cítrica por lodo ativado por batelada (LAB): tratabilidade e microbiologia. Dissertação de doutorado, Faculdade de Engenharia Civil, Universidade Estadual de Campinas, 2000
DORNELAS, J. C. Tratamento do efluente li-
POVINELLI, J., MATHEUS, C. E. \& FRAGIACOMO, P. Aclimatação de um residuo industrial. Revista DAE, 49(154):24-28,1989.

RÜGER, H.J., TAN, T. L. Separation of Alcaligenes denitrificans sp. nov. nom. rev. from Alcaligenes faecalis on the basis of DNA base composition, DNA homology and nitrate reduction. Int. J. Syst. Bacteriol. (33) 85-89, 1983

SHAW, P. E. Essenstial oils. Citrus Science and Technology Vol 1, The AVI publishing Company, Inc., Westport, Conn. pp-430-435, 1977

Standard Methods for the Examination of Water and Wastewater 1990.

SPERLING, M.V. Princípios básicos do trata mento de esgotos. Vol 2. Belo Horizonte: Departamento de engenharia sanitária e ambiental, Universidade Federal de Minas Gerais, 1997.

THOMAS, A.F. \& BESSIÉRE, Y. Limonene. Natural products reports. p 291-309, 1989.

URIBE, S \& PENA, A. Toxicity of alleopathic monoterpene suspensión on yeast, dependence on droplet size. Journal of chemical ecology, v. 16 , p. $1399-1408,1990$.

VAZOLLER, R. F. Jornal do conselho regional de biologia, ano IV, $\mathrm{n}^{\circ} 34,08 / 1997$.

VAZOLLER. R. F. Microbiologia de lodos ativados. São Paulo: CETESB, Série manuais. 1989

Endereço para correspondência:

\section{Alexandre Nunes Ponezi \\ Divisão de Microbiologia \\ CPQBA/UNICAMP \\ Caixa Postal 6171}

I308 I-970 Campinas - SP - Brasil

Tel.: (19) 3884-7500

Fax: (19) 3884-78II

E-mail:ponezi@cpqba.unicamp.br

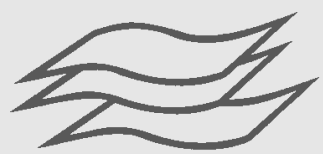

FUNDO EDITORIAL ABES SANEAMENTO E MEIO AMBIENTE

Listagem organizada por assunto e tabela de preços - www.abes-dn.org.br 